\title{
Beryllium-10 and aluminum-26 in individual cosmic spherules from Antarctica
}

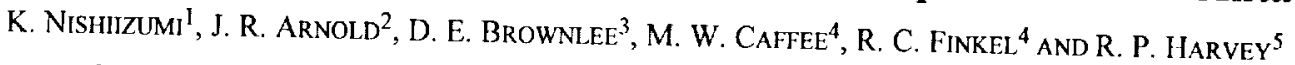 \\ ${ }^{I}$ Space Sciences Laboratory, University of California, Berkeley, California 94720, USA \\ ${ }^{2}$ Department of Chemistry, University of California/San Diego, La Jolla, California 92093-0524, USA \\ ${ }^{3}$ Department of Astronomy, University of Washington, Seattle, Washington 98195, USA \\ ${ }^{4}$ Center for Accelerator Mass Spectrometry, Lawrence Livermore National Laboratory, \\ L-397, P. O. Box 808, Livermore, California 94551, USA \\ ${ }^{5}$ Department of Geological Sciences, Case Western University, Cleveland, Ohio 44106-7216, USA
}

(Received 1995 February 17; accepted in revised form 1995 August 22)

\begin{abstract}
We present data for the cosmogenic nuclides ${ }^{10} \mathrm{Be}$ and ${ }^{26} \mathrm{Al}$ in a suite of 24 extraterrestrial
spherules, collected from Antarctic spherules, collected from Antarctic moraines and deep sea sediments. All of the 10 large spherules collected in glacial till at Lewis Cliff are extraterrestrial. As in earlier work, the great majority of particles show prominent solar cosmic-ray (SCR) production of ${ }^{26} \mathrm{Al}$, indicating bombardment ages on the order of $10^{6}$ years or even longer. These long ages are in direct contradiction to model ages for small particles in the inner Solar System and may require reconsideration of models of small particle lifetimes. A small fraction of meteoroid spall droplets. We believe that most of the not much larger than their present size. The content of in situ produced ${ }^{10} \mathrm{Be}$ and ${ }^{26} \mathrm{Al}$ in quartz pebbles in the same moraine suggests that these
spherules may have on average a significant terrestrial age.
\end{abstract}

\section{INTRODUCTION}

Cosmic spherules and fragments in the size range $0.1-1 \mathrm{~mm}$, originally extracted magnetically from deep-sea sediments (Brownlee et al., 1979; Millard and Finkelman, 1970; Murray and Renard, 1883; Murrell et al., 1980) have now been isolated from ice in Greenland and Antarctica (Harvey and Maurette, 1990; Koeberl and Hagen, 1989; Maurette et al., 1986).

Concentrations of cosmogenic radionuclides have been measured in a representative suite of deep-sea spherules and Greenland particles by accelerator mass spectrometry (AMS) (Nishiizumi et al., 1991; Raisbeck and Yiou, 1987; Raisbeck et al., 1985b). Also, light noble gases were measured in similar particles by an ultrasensitive noble gas mass spectrometer (Olinger et al., 1990). The data show that most of the particles had lifetimes in space of $>10^{6}$ years. These lifetimes based on measurements are much longer than collision lifetimes expected of similar sized particles from model calculations, which predict a few times $10^{4}$ ycars (Dohnanyi, 1978; Grün et al., 1985). Recently cosmic spherules have been found in glacial till in Antarctica (Harvey and Maurette, 1990; Koeberl and Ilagen, 1989). These spherules represent a new source of extraterrestrial materials from which considerable information about solar system processes may be learned. As new sources of these materials are discovered it becomes increasingly important for us to understand the nature and origin of these particles.

Several questions secm important to us at this stage: Are these new spherules found in the glacial till of extraterrestrial origin? What is the relationship among the deep-sea spherules, Greenland particles, and those from the Antarctic? What is the distribution of micrometeoroid lifetimes in space? Since melt droplets from larger metcoroids must occur, how can they be identified and what is their proportion relative to spherules produced by atmospheric melting of initially small particles? We measured the cosmogenic radionuclides ${ }^{10} \mathrm{Be}\left(\mathrm{T}_{1 / 2}=1.5 \times 10^{6}\right.$ years $)$ and ${ }^{26} \mathrm{Al}\left(\mathrm{T}_{1 / 2}=7.05 \times 10^{5}\right.$ years) in 16 individual spherules collected from glacial till in Antarctica along with 8 additional decp-sea spherules to investigate these questions. Results for 6 of the Antarctic particles were previously reported (Nishiizumi et al., 1992).

\section{SAMPLE DESCRIPTION AND EXPERIMENTAL METHODS}

The concentrations of cosmogenic ${ }^{10} \mathrm{Be}$ and ${ }^{26} \mathrm{AI}$ and major element chemical compositions were measured in 10 individual large spherules $(150-420 \mu \mathrm{g})$ from Antarctica. These spherules (IC-7-I.C-16) were hand picked after sieving, using non-magnetic brushes under a binocular microscope, from glacial till collected near Lewis Cliff, Antarctica $\left(84^{\circ} 3^{\prime} \mathrm{S}\right.$, $161^{\circ} 6^{\prime} \mathrm{E}, 2200 \mathrm{~m}$ elevation) (I Tarvey and Maurettc, 1990; Koeberl and Ilagen, 1989). In addition to these spherules, we analyzed eight individual deep-sea spherules (LJ-36-LJ-2737) from the Millard collection, described by Murrell et al. (1980). These spherules were collected from Pacific Ocean red clay $\left(18^{\circ} 41^{\prime} \mathrm{N}, 123^{\circ} 47^{\prime} \mathrm{W}, 4280 \mathrm{~m}\right.$ depth). After weights and diameters were measured, all particles were individually mounted in acrylic resin, and a small surface was polished flat with AI oxide followed by $\mathrm{C}$ coating. The quantitative elemental analysis of these polished surfaces was performed using a JEOL 733 Superprobe. Magnesium, $\mathrm{AI}, \mathrm{Si}, \mathrm{Ca}, \mathrm{Cr}, \mathrm{Mn}$, $\mathrm{Fe}$, and $\mathrm{Ni}$ were measured at $15 \mathrm{kV}$ with a spot size of $30 \mu \mathrm{m}$. Results are shown in Table I. The probe analysis errors are $-1 \%$ for $\mathrm{Mg}, \mathrm{Si}$, and $\mathrm{Fe}$, $\sim 2 \%$ for $\mathrm{Al}$ and $\mathrm{Ca}$ (because of their lower abundance), $<10 \%$ for $\mathrm{Cr}$ and $\mathrm{Mn}$, and relative errors for $\mathrm{Ni}$ range from $10 \%$ to $20 \%$. After electron microprobe analysis, each particle was separated from the resin with chloroform and washed with ethanol and deionized water in an ultrasonic bath. The individual weights were measured again. The samples were dissolved with $\mathrm{HF}-\mathrm{HNO}_{3}$ mixture along with $\mathrm{Be}(0.5 \mathrm{mg})$ and $\mathrm{Al}(1.0 \mathrm{mg})$ carriers. Beryllium and Al were chemically separated and purified for AMS. These procedures are similar to our earlier work (Nishizumi et al., 1991). The Be and ${ }^{26} \mathrm{Al}$ concentrations were determined using the Lawrence Livermore National Laboratory tandem accelerator (Davis et al. 1990). The measured ${ }^{10} \mathrm{Be} / \mathrm{Be}$ ratios ranged from $\mathrm{I} \times 10^{-14}$ to $2 \times 10^{-13}$ and the measured ${ }^{26} \mathrm{Al} / \mathrm{Al}$ ratios from $\mathrm{I} \times 10^{-14}$ to $8 \times 10^{-13}$. After correcting for ${ }^{10} \mathrm{Be}$ background due to ${ }^{10} \mathrm{~B}$ and for chemical blank $\left(6 \times 10^{-15}\right.$ for ${ }^{10} \mathrm{Be} / \mathrm{Be}$ and $1 \times 10^{-14}$ for $\left.{ }^{26} \mathrm{Al} / \mathrm{Al}\right)$, the measured ratios were normalized
to ICN $10 \mathrm{Be}$ and to ICN ${ }^{10} \mathrm{Be}$ and NBS ${ }^{26} \mathrm{Al}$ standards, which were diluted at La Jolla. The corrected ratios were converted to atom concentration (atom/g sample) and
activities (dpm/ $/ \mathrm{kg}$. The activities (dpm/ $\mathrm{kg}$ sample). The results are shown in Table 2 along with
density of the samples.

\section{RESULTS AND DISCUSSION}

Table 1 gives the diameter, mass, and major-element composition ( $w \mathrm{t} \%$ ) of Antarctic spherules, LC-7-LC-16, and deepsea spherules, LJ-36-IJJ-2737, along with the results of previous 
TABLE 1. Chemical composition of Antarctic spherules and deep-sea spherules.

\begin{tabular}{|c|c|c|c|c|c|c|c|c|c|c|c|c|}
\hline & $\begin{array}{l}\text { Size } \\
(\mu \mathrm{m}) \\
\end{array}$ & $\begin{array}{c}\text { Before } \\
\text { Polish } \\
\text { Wt }(\mu \mathrm{g})\end{array}$ & $\begin{array}{c}\text { After } \\
\text { Polish } \\
\text { Wt }(\mu \mathrm{g})\end{array}$ & $\begin{array}{l}\mathrm{Mg} \\
(\%)\end{array}$ & $\begin{array}{c}\mathrm{AI} \\
(\%)\end{array}$ & $\begin{array}{l}\mathrm{Si} \\
(\%)\end{array}$ & $\begin{array}{l}\mathrm{Ca} \\
(\%)\end{array}$ & $\begin{array}{l}\mathrm{Cr}_{\mathrm{r}} \\
(\%)\end{array}$ & $\begin{array}{l}\mathrm{Mn} \\
(\%)\end{array}$ & $\begin{array}{l}\mathrm{Fe} \\
(\%)\end{array}$ & $\begin{array}{l}\mathrm{Ni} \\
(\%)\end{array}$ & $\begin{array}{c}\mathrm{O} \\
(\%)\end{array}$ \\
\hline \multicolumn{13}{|c|}{$\begin{array}{lc}\text { Antarctic Spherules } \\
\text { LC-1* } & 720 \times 980\end{array}$} \\
\hline LC-1* & $720 \times 980$ & 496.5 & 453.5 & 17.2 & 1.12 & 22.0 & 1.47 & 0.06 & 0.33 & 15.3 & 0.12 & 42.4 \\
\hline LC-2* & 920 & 781.9 & 755.7 & 18.4 & 1.26 & 21.2 & 3.44 & 0.12 & 0.32 & 12.7 & 0.06 & 42.5 \\
\hline LC-3* & 700 & 404.5 & 382.1 & 16.1 & 2.07 & 23.6 & 1.03 & 0.19 & 0.29 & 12.9 & 0.04 & 43.8 \\
\hline LC-4* & 700 & 288.8 & 248.3 & 22.0 & 1.69 & 22.1 & 2.02 & 0.00 & 0.25 & 8.0 & 0.06 & 43.9 \\
\hline LC-5* & 670 & 447.4 & 412.4 & 15.0 & 1.24 & 14.7 & 3.40 & 0.14 & 0.13 & 28.2 & 0.07 & 37.1 \\
\hline LC- $6^{*}$ & 550 & 251.2 & 219.5 & 18.4 & 2.29 & I8.5 & 1.87 & 0.00 & 0.14 & 17.1 & 0.00 & 41.7 \\
\hline LC-7 & 650 & 352.5 & 322.6 & 16.9 & 1.32 & 23.3 & 2.17 & 0.01 & 0.27 & 11.2 & 0.13 & 44.6 \\
\hline LC-8 & 510 & 145.3 & 127.1 & 18.0 & 1.79 & 20.4 & 1.99 & 0.02 & 0.24 & 14.7 & 0.31 & 42.5 \\
\hline LC-9 & 660 & 420.9 & 286.6 & 10.3 & 3.96 & 23.6 & 3.78 & 0.08 & 0.44 & 13.2 & 0.01 & 44.4 \\
\hline LC-10 & 640 & 383.4 & 299.3 & 15.0 & 1.59 & 16.9 & 1.30 & 0.29 & 0.22 & 25.9 & 0.86 & 37.9 \\
\hline LC-[1] & 620 & 385.4 & 335.1 & 18.7 & 1.68 & 21.7 & 1.53 & 0.05 & 0.30 & 12.4 & 0.08 & 43.5 \\
\hline LC- 12 & $520 \times 650$ & 269.7 & 177.5 & {$[8.8$} & 1.68 & 20.0 & 2.09 & 0.10 & 0.23 & 14.2 & 0.44 & 42.4 \\
\hline LC -13 & 620 & 271.8 & 242.1 & 20.5 & 1.86 & 23.6 & 1.65 & 0.06 & 0.35 & 5.9 & 0.00 & 46.0 \\
\hline LC-14 & 560 & 239.2 & 214.8 & 17.0 & 2.43 & 18.1 & 2.06 & 0.18 & 0.17 & 19.2 & 0.34 & 40.3 \\
\hline LC-15 & $640 \times 770$ & 393.0 & 340.2 & 18.5 & 1.24 & 20.8 & 0.97 & 0.18 & 0.33 & 15.9 & 0.00 & 42.0 \\
\hline LC-16 & 800 & 271.9 & 233.7 & 15.9 & 1.65 & 22.5 & 2.03 & 0.14 & 0.27 & 13.1 & 0.04 & 44.3 \\
\hline \multicolumn{13}{|c|}{$\begin{array}{lr}\text { Deep-Sea } & \text { Spherules } \\
\text { LJ-36 } & 490\end{array}$} \\
\hline LJ-36 & 490 & 172.1 & 141.2 & 7.8 & 0.57 & 12.4 & 0.22 & 0.18 & 0.14 & 34.6 & 0.05 & 43.9 \\
\hline LJ-2692 & 390 & 93.5 & 57.5 & 8.6 & 1.08 & 9.8 & 0.34 & 0.32 & 0.03 & 42.7 & 2.71 & 34.4 \\
\hline LJ-2722 & 380 & 155.5 & 127.9 & 0.0 & 0.00 & 0.0 & 0.00 & 0.15 & 0.00 & 73.8 & 0.40 & 25.6 \\
\hline LJ-2730 & 450 & 214.8 & 191.6 & 0.0 & 0.00 & 0.0 & 0.01 & 0.00 & 0.02 & 72.4 & 2.80 & 24.8 \\
\hline LJ-2732 & 460 & 210.3 & 174.3 & 6.1 & 0.34 & 6.9 & 0.21 & 0.10 & 0.00 & 55.2 & 2.94 & 28.2 \\
\hline LJ-2733 & $420 \times 530$ & 248.0 & 223.8 & 0.0 & 0.00 & 0.0 & 0.00 & 0.13 & 0.00 & 70.8 & 2.99 & 26.1 \\
\hline LJ-2736 & $400 \times 430$ & 93.4 & 81.8 & 2.8 & 0.20 & 6.5 & 0.07 & 0.07 & 0.52 & 51.7 & 0.00 & 38.0 \\
\hline LJJ-2737 & $430 \times 570$ & 197.5 & 144.5 & 9.6 & 0.54 & 10.9 & 0.40 & 0.18 & 0.04 & 41.1 & 0.11 & 37.1 \\
\hline
\end{tabular}

measurements of other Antarctic spherules, LC-1-LC-6, for comparison (Nishiizumi et al., 1992). Oxygen concentration is estimated by difference and shown in the table. Spherule LC-1 is extremely unusual; it is a black, glassy, pear-shape rather than rounded or elliptical. Even allowing for internal holes in LC-4 and LC-16, the mean density of these particles, average $=2.35 \pm 0.56$ $\mathrm{g} / \mathrm{cm}^{3}$, is clearly lower than that of stony deep-sea spherules, 3.12 $\mathrm{g} / \mathrm{cm}^{3}$ (Murrell et al., 1980), consistent with their lower mean Fe content.

Samples LJ-2722, 2730, and 2733 are Fe particles, which appear to be oxidized to a composition in the range of $\mathrm{FeO}-\mathrm{Fe}_{2} \mathrm{O}_{3}$. Concentrations of $\mathrm{Fe}$ and $\mathrm{O}$ for both Antarctic spherules and deepsea spherules are anticorrelated, as shown in Fig. I $(\mathrm{R}=0.988)$. The plot includes all Lewis Cliff particles and both stony and $\mathrm{Fe}$ deep-sea spherules except LJ-36 and 2736. Nickel concentrations in all Lewis Cliff particles except LC-10 are depleted compared to deep-sea spherules.

A Mg-Si-Fe ternary diagram is useful to show how the Lewis Cliff compositions compare with the compositions of 410 magnetically collected deep-sea spherules (KK1) (Brownlee et al., 1983). As shown in Fig. 2, an abnormal fraction of the Mg-Si-Fe compositions are Si-rich or Fe-poor relative to the main cluster of KKI compositions. This may be partly explained by the fact that the KK1 deep-sea spherules were collected magnetically, so there is a bias favoring Fe-rich particles in the KK1 collection. It is also possible that the Lewis Cliff moraine spherules are biased towards lower density materials that are more easily carried by wind.

Although compositions of Lewis Cliff particles are slightly different from deep-sea spherules, all 16 Lewis Cliff particles are stony type. Murrell et al. (1980) and our unpublished work indicate that nearly half of the deep-sea spherules are oxidized Fe particles.
In addition to the difference of collection methods, magnetic (deepsea spherules) $v s$. hand picking (Lewis Cliff), it seems that the aridity and lack of liquid water of the Antarctic environment are more favorable for survival of stony particles than conditions on the ocean floor. This aridity also results in long terrestrial ages of Antarctic meteorites and low erosion rates of Antarctic surface rocks. Assuming the Lewis Cliff particles and deep-sea spherules had similar origins, the higher abundance of stony types among the Lewis Cliff particles indicates that the stony particles in deep-sea spherules may be destroyed comparatively quickly by weathering or

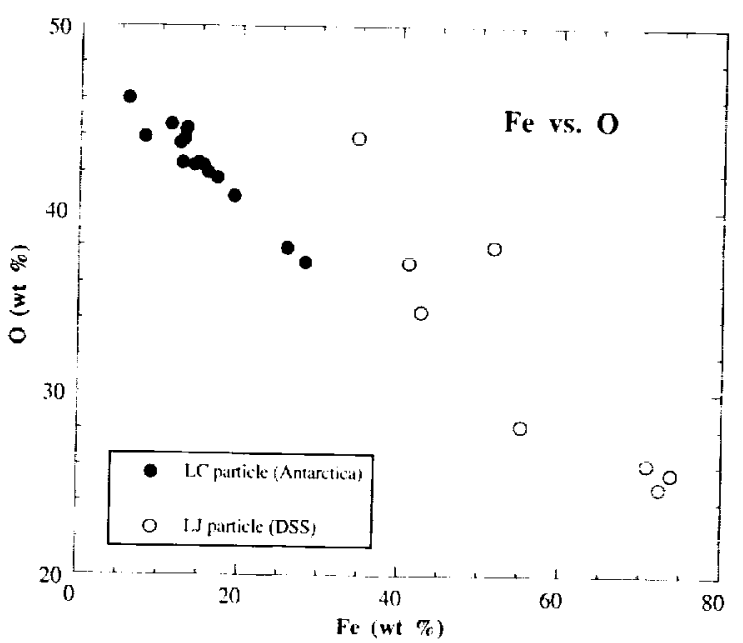

Fig. 1. Concentrations of $\mathrm{O} v \mathrm{~s}$. Fe in Antarctic spherules (LC) and deep-sea spherules $(\mathrm{LJ})$. Concentration of $\mathrm{Fe}$ is anticorrelated with $\mathrm{O}(\%)=47-$
$0.304 \mathrm{Fe}(\%)(\mathrm{R}=0.988)$. 
TABLE 2. Beryllium-10 and aluminum-26 concentrations in Antarctic and deep-sea spherules.

\begin{tabular}{|c|c|c|c|c|c|c|c|}
\hline & $\begin{array}{c}\text { Before } \\
\text { Polish } \\
\text { Wt }(\mu \mathrm{g})\end{array}$ & $\begin{array}{l}\text { Density } \\
\left(\mathrm{g} / \mathrm{cm}^{3}\right)\end{array}$ & $\begin{array}{c}{ }^{10} \mathrm{Be} \\
\left(10^{9} \text { atom/g) }\right.\end{array}$ & $\begin{array}{c}{ }^{10} \mathrm{Bc} \\
(\mathrm{dpm} / \mathrm{kg})\end{array}$ & $\begin{array}{c}{ }^{26} \mathrm{Al} \\
\left(10^{9} \text { atom/g }\right)\end{array}$ & $\begin{array}{c}26 \mathrm{Al} \\
(\mathrm{dpm} / \mathrm{kg})\end{array}$ & $\begin{array}{l}{ }^{26} \mathrm{Al} /{ }^{10} \mathrm{Be} \\
(\mathrm{dpm} / \mathrm{dpm})\end{array}$ \\
\hline \multicolumn{8}{|c|}{ Antarctic Spherules } \\
\hline LC- $1^{*}$ & 496.5 & 1.87 & $18.8 \pm 1.0$ & $16.5 \pm 0.9$ & $89.0 \pm 4.0$ & $167.3 \pm 7.5$ & $10.1 \pm 0.7$ \\
\hline $\mathrm{LC}-2^{*}$ & 781.9 & 1.92 & $7.1 \pm 0.4$ & $6.3 \pm 0.3$ & $74.5 \pm 3.3$ & $139.3 \pm 6.1$ & $22.3 \pm 1.5$ \\
\hline LC-3* & 404.5 & 2.25 & $4.6 \pm 0.4$ & $4.0 \pm 0.4$ & $50.6 \pm 2.5$ & $94.5 \pm 4.7$ & $23.4 \pm 2.3$ \\
\hline LC-4* & 288.8 & 1.61 & $23.0 \pm 1.2$ & $20.2 \pm 1.0$ & $130.7 \pm 5.3$ & $244.3 \pm 10.0$ & $12.1 \pm 0.8$ \\
\hline LC-5* & 447.4 & 2.84 & $16.3 \pm 0.8$ & $14.3 \pm 0.7$ & $101.5 \pm 4.6$ & $189.8 \pm 8.6$ & $13.2 \pm 0.9$ \\
\hline LC- $6^{*}$ & 251.2 & 2.88 & $18.0 \pm 1.0$ & $15.8 \pm 0.9$ & $19.2 \pm 2.0$ & $35.9 \pm 3.8$ & $2.3 \pm 0.3$ \\
\hline $\mathrm{LC}-7$ & 352.5 & 2.45 & $6.7 \pm 0.8$ & $5.9 \pm 0.7$ & $60.6 \pm 5.2$ & $113.2 \pm 9.7$ & $19.3 \pm 2.8$ \\
\hline LC-8 & 145.3 & 2.09 & $19.4 \pm 1.5$ & $17.0 \pm 1.3$ & $97.6 \pm 4.7$ & $182.5 \pm 8.8$ & $10.7 \pm 1.0$ \\
\hline LC-9 & 420.9 & 2.79 & $5.7 \pm 0.8$ & $5.0 \pm 0.7$ & $42.1 \pm 2 . I$ & $78.7 \pm 3.9$ & $15.8 \pm 2.3$ \\
\hline LC-10 & 383.4 & 2.79 & $13.3 \pm 1.4$ & $11.7 \pm 1.2$ & $30.5 \pm 1.8$ & $57.0 \pm 3.4$ & $4.9 \pm 0.6$ \\
\hline LC-11 & 385.4 & 3.09 & $4.4 \pm 0.5$ & $3.9 \pm 0.4$ & $50.5 \pm 3.0$ & $94.5 \pm 5.6$ & $24.4 \pm 3.0$ \\
\hline LC- 12 & 269.7 & 2.93 & $9.0 \pm 0.8$ & $7.9 \pm 0.7$ & $54.4 \pm 4.7$ & $101.6 \pm 8.7$ & $12.8 \pm 1.6$ \\
\hline LC-13 & 271.8 & 2,18 & $3.7 \pm 0.7$ & $3.3 \pm 0.7$ & $12.1 \pm 1.4$ & $22.7 \pm 2.6$ & $6.9 \pm 1.6$ \\
\hline IC- 14 & 239.2 & 2.60 & $9.3 \pm 0.7$ & $8.2 \pm 0.6$ & $53.2 \pm 2.7$ & $99.5 \pm 5.0$ & $12.1 \pm 1.1$ \\
\hline LC-15 & 393.0 & 2.38 & $18.5 \pm 0.8$ & $16.3 \pm 0.7$ & $40.0 \pm 1.9$ & $74.8 \pm 3.5$ & $4.6 \pm 0.3$ \\
\hline LC-16 & 271.9 & 1.01 & $5.6 \pm 0.8$ & $4.9 \pm 0.7$ & $57.4 \pm 3.1$ & $107.3 \pm 5.8$ & $22.0 \pm 3.3$ \\
\hline \multicolumn{8}{|c|}{$\begin{array}{l}\text { LC-16 } \\
\text { Deep-Sea Spherules }\end{array}$} \\
\hline LJ-36 & 172.1 & 2.79 & $13.3 \pm 1.5$ & $11.7 \pm 1.3$ & $4.8 \pm 1.6$ & $9.0 \pm 2.9$ & $0.8 \pm 0.3$ \\
\hline LJ-2692 & 93.5 & 3.01 & $12.0 \pm 3.0$ & $10.6 \pm 2.6$ & $47.5 \pm 13.6$ & $88.8 \pm 25.4$ & $8.4 \pm 3.2$ \\
\hline LJ -2722 & 155.5 & $5.4 \mathrm{I}$ & $22.8 \pm 2.3$ & $20.0 \pm 2.0$ & $15.4 \pm 2.8$ & $28.8 \pm 5.2$ & $1.4 \pm 0.3$ \\
\hline LJ-2730 & 214.8 & 4.50 & $8.0 \pm 1.3$ & $7.0 \pm 1.2$ & $1.3 \pm 0.8$ & $2.5 \pm 1.6$ & $0.4 \pm 0.2$ \\
\hline I.J-2732 & 210.3 & 4.13 & $2.9 \pm 0.9$ & $2.6 \pm 0.8$ & $18.7 \pm 2.2$ & $35.0 \pm 4.2$ & $13.6 \pm 4.4$ \\
\hline LJ-2733 & 248.0 & 5.07 & $3.6 \pm 1.1$ & $3.1 \pm 0.9$ & $0.2 \pm 0.9$ & $0.4 \pm 1.7$ & $0.1 \pm 0.6$ \\
\hline LJ-2736 & 93.4 & 2.59 & $10.8 \pm 2.5$ & $9.5 \pm 2.2$ & $3.4 \pm 3.0$ & $6.3 \pm 5.6$ & $0.7 \pm 0.6$ \\
\hline LJ-2737 & 197.5 & 3.58 & $8.6 \pm 1.4$ & $7.5 \pm 1.3$ & $24.4 \pm 5.6$ & $45.6 \pm 10.4$ & $6.0 \pm 1.7$ \\
\hline
\end{tabular}

*(Nishiizumi et al., 1992).

there is a strong collection bias against non-magnetic properties. It is also possible that the moraine spherules are highly selected by the aeolian process that concentrated them. We may have underestimated the flux of stony particles based on deep-sea spherule results (Maurette et al., 1987).

So far as the stony particles are concerned, the cosmogenic radionuclide data are consistent with all samples being members of the same population. Unquestionably, they are all extraterrestrial, validating the collection and selection methods employed.

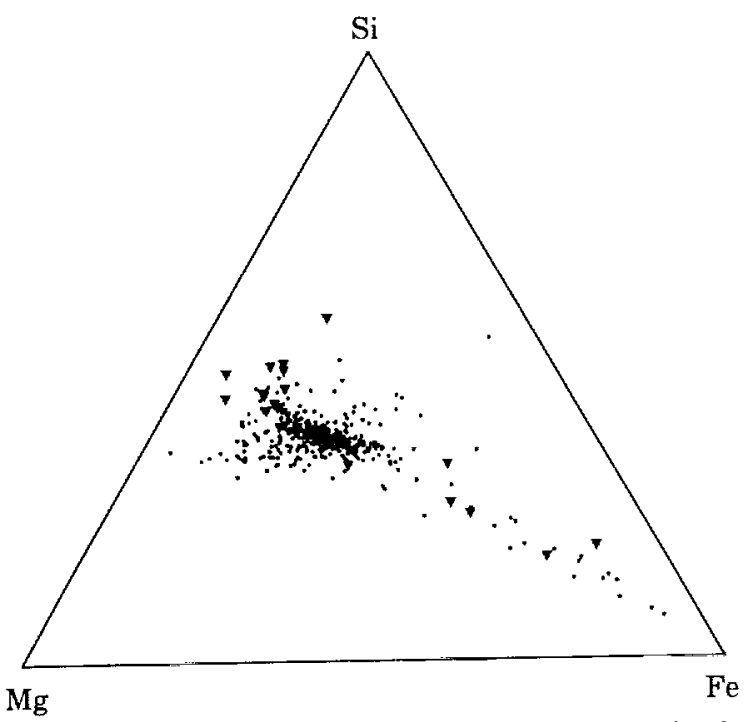

FIG 2. Ternary diagram of Mg-Si-Fe (atom fractions). Small dots indicate 410 magnetically collected dcep-sea spherules (Brownlee et al., 1983). Filled triangles indicate $\mathrm{Mg}-\mathrm{Si}$-Fe compositions of Antarctic and deep-sea spherules from this work.
The production rates of ${ }^{10} \mathrm{Be}$ and ${ }^{26} \mathrm{Al}$ in cosmic spherules for various shielding conditions and sizes have been discussed (Nishiizumi et al., 1991) using improved Reedy-Arnold model calculations (Reedy, 1987, 1990; Reedy and Arnold, 1972). Recently, Reedy and Masarik (1995) updated their model calculations. The results are summarized below. We used the average chemical composition of stony type deep-sea spherules for these calculations: $17 \% \mathrm{Mg}, 1.4 \% \wedge \mathrm{l}, 16.5 \% \mathrm{Si}, 1.4 \% \mathrm{Ca}, 0.2 \%$ $\mathrm{Mn}, 22.0 \% \mathrm{Fe}, 0.5 \% \mathrm{Ni}$, and $40.7 \% \mathrm{O}$. The average chemical compositions of 16 Lewis Cliff particles are similar to these values, with slightly higher concentrations of $\mathrm{Al}$ and $\mathrm{Si}$ and lower concentration of $\mathrm{Fe}$ compared to deep-sea spherules. Because of the variety of chemical compositions for individual particles and the possible effects of terrestrial weathering, we used the same average chemical composition for cosmogenic nuclide calculation of Lewis Cliff particles.

The major target element for ${ }^{10} \mathrm{Be}$ production is $\mathrm{O}$. The $\mathrm{O}$ concentrations of Lewis Cliff particles are $42.4 \pm 2.4 \%$, and the ${ }^{10} \mathrm{Be}$ production rate calculation for stony particles would not be scnsibly affected if individual compositions were used. For ${ }^{26} \mathrm{Al}$ production, the major targets are $\mathrm{Si}$ and $\mathrm{Al}$. Although the production rate of solar cosmic-ray-produced ${ }^{26} \mathrm{Al}$ is sensitive to the $\mathrm{Mg}$ and $\mathrm{Al}$ concentrations, the average chemical composition was adopted. The uncertainty of depth and size of individual particles has a much larger influence than composition differences for the solar cosmic-ray calculation.

The saturation activity of ${ }^{10} \mathrm{Be}$ in small stony type objects (less than a few $\mathrm{mm}$ in diameter) is estimated to be $\sim 8 \mathrm{dpm} / \mathrm{kg}$ (Reedy, 1987). The saturation value of ${ }^{10} \mathrm{Be}$ on the surface of a large body ( $2 \pi$ irradiation), such as an asteroid, is somewhat higher, $10-12$ $\mathrm{dpm} / \mathrm{kg}$. In ordinary-sized chondrites (radius $\leq 40 \mathrm{~cm}$ ), the 
saturation value of ${ }^{10} \mathrm{Be}$ is $15-25 \mathrm{dpm} / \mathrm{kg}$ (Nishiizumi, 1987). The differences in saturation value are accounted for by the presence of secondary neutrons in larger bodies. Since solar cosmic-ray production of ${ }^{10} \mathrm{Be}$ is very low (Nishiizumi et al., 1988), the concentration of ${ }^{10} \mathrm{Be}$ in an object is determined only by galactic cosmic-ray production, which is rather constant near the preatmospheric surface of any body. On the other hand, the ${ }^{26} \mathrm{Al}$ concentration has a steep depth dependence because solar cosmic-ray production is important. The solar cosmic-ray production rate of ${ }^{26} \mathrm{Al}$ also increases with decreasing size of small objects (less than a few $\mathrm{cm}$ in diameter). At 1 A.U., the production rates of ${ }^{26} \mathrm{Al}$, due to solar cosmic-ray bombardment, range from 410 atom $/ \mathrm{kg} \min \left(0.1 \mathrm{~g} / \mathrm{cm}^{2}\right.$ radius $)$ to 118 atom $/ \mathrm{kg} \min \left(5.0 \mathrm{~g} / \mathrm{cm}^{2}\right.$ radius) for the $4 \pi$ case and from 260 atom $/ \mathrm{kg} \min \left(0.1 \mathrm{~g} / \mathrm{cm}^{2}\right.$ depth) to $14 \mathrm{atom} / \mathrm{kg} \min \left(5.0 \mathrm{~g} / \mathrm{cm}^{2} \mathrm{depth}\right)$ for $2 \pi$ case (Reedy, pers. comm.). Galactic cosmic-ray produced${ }^{26} \mathrm{Al}$ dominates below a few $\mathrm{cm}$ from the surface, at $-40-75 \mathrm{dpm} / \mathrm{kg}$ for typical-sized chondrites (Nishiizumi, 1987). The saturation value of ${ }^{26} \mathrm{Al}$ in a large body ( $2 \pi$ irradiation) is $\sim 30 \mathrm{dpm} / \mathrm{kg}$ below a few $\mathrm{cm}$ from the surface.

To summarize, the ${ }^{10} \mathrm{Bc}$ content can, thus, be used to estimate exposure time in space and, also, the size of the object. The ${ }^{26} \mathrm{Al}$ content, on the other hand, is used to estimate shielding depth of irradiation since ${ }^{26} \mathrm{Al}$ is produced by solar cosmic-ray only near the surface.

The observed ${ }^{10} \mathrm{Be}$ activities of Lewis Cliff particles are $\sim 20$ $\mathrm{dpm} / \mathrm{kg}$ or less. These Lewis Cliff spherules show clear evidence of cxposure to galactic cosmic-ray bombardment on time scales from $-10^{6}$ up to as much as $10^{7}$ years. Many Lewis Cliff spherules contain high ${ }^{26} \mathrm{Al}$, up to $-240 \mathrm{dpm} / \mathrm{kg}$, which is produced by solar cosmic-ray bombardment of small objects in space or very near the surface $\left(<1 \mathrm{~g} / \mathrm{cm}^{2}\right)$ of larger objects. Cosmogenic nuclide contents in Lewis Cliff particles are very similar to those in deep-sea spherules and, although the data set is small, also for Greenland particles. To date, the ${ }^{10} \mathrm{Be}$ and ${ }^{26} \mathrm{Al}$ concentrations in 42 individual particles (16 Lcwis Cliff particles from Antarctica, 2 Greenland particles and 24 deep-sea spherules), which have some chemical analysis in addition to cosmogenic nuclide concentration, are known (Nishiizumi et al., 1991, 1992; Raisbeck et al., 1985b). These data can now be used to study their lifetimes in space and the conditions under which they were bombarded by galactic cosmic-ray and solar cosmic-ray particles. Figure 3 illustrates ${ }^{26} \mathrm{Al}$ vs. ${ }^{10} \mathrm{Be}$ in 41 stony particles. One stony decp-sea spherule (KK2-5) contains high ${ }^{10} \mathrm{Be}$ $(50 \pm 7 \mathrm{dpm} / \mathrm{kg})$ (Raisbeck et al., 1985a) and is not shown in the figure. Beryllium-10 concentrations in five deep-sea spherules are shown only as upper limits. The solid line and dashed lines indicate ${ }^{26} \mathrm{Al}$ and ${ }^{10} \mathrm{Be}$ in typical sized meteorites and their ranges.

In previous studies, the high ${ }^{26} \mathrm{Al}$ values were thought to reflect cosmic-ray irradiation of small objects ( $4 \pi$ bombardment) or of the surface of asteroids that are meters or more in diameter $(2 \pi$ bombardment) (Nishiizumi et al., 1991; Raisbeck et al., 1985b). However, such a model cannot explain the high ${ }^{10} \mathrm{Be}(\geq 15 \mathrm{dpm} / \mathrm{kg})$ found in 8 out of 42 particles, including those described in previous work (Nishiizumi et al., 1991; Raisbeck et al., 1985b). These levels of ${ }^{10} \mathrm{Be}$, which are similar to ordinary chondritic levels, suggest that this population of particles may have received galactic cosmic-ray bombardment in objects of size often encountered in meteorites (a few $\mathrm{cm}$ to $40 \mathrm{~cm}$ ). The combination of solar cosmic-ray produced${ }^{26} \mathrm{Al}$ and high ${ }^{10} \mathrm{Be}$ can be produced at the surface of such bodies. Two possible sources are (1) surface erosion products from meteorioids in their orbits, or (2) melt droplets from larger

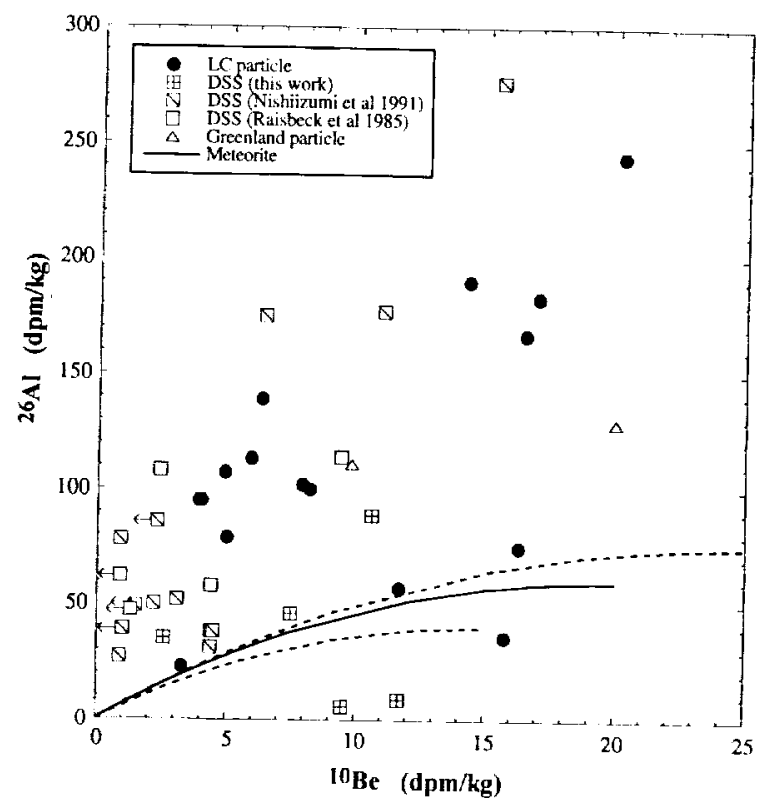

FIG. 3. The correlation between ${ }^{10} \mathrm{Be}$ activity $(\mathrm{dpm} / \mathrm{kg})$ and ${ }^{26} \mathrm{AI}$ activity (dpm/kg) for Antarctic, Greenland, and deep-sea spherules. The solid line and dashed lines indicate ${ }^{10} \mathrm{Be}$ and ${ }^{26} \mathrm{Al}$ concentrations in typical sized chondrites. Exposure age increases along the line to the right.

meteoroids during atmospheric entry. The latter is an old idea for the origin of deep-sea spherules. Even though a large fraction of the preatmospheric mass of meteoroids is lost to ablation during passage through the atmosphere (Bhandari et al., 1980), for meteorites near the smaller end of the size range, a significant fraction of this ablated material would have been exposed to cosmic rays at $<1 \mathrm{~cm}$ depth. The very high ${ }^{10} \mathrm{Be}$ in one particlc, KK2-5, measured by Raisbeck et al. (1985a) cannot be explained by any of these models.

For this and an earlier group of Lewis Cliff and deep-sea spherules, in six cases (LC-6, LC-10, LC-13, LC-15, LJ-527, LJ2737) the contents of ${ }^{10} \mathrm{Be}$ and ${ }^{26} \mathrm{Al}$ are consistent with their being spall droplets from a depth $>3 \mathrm{~cm}$ in meteoroids. Thus far the ${ }^{10} \mathrm{Be}$ and ${ }^{26} \mathrm{Al}$ data would allow 6 out of the 42 stony objects measured to be explained with an ablation hypothesis. In all other cases, clear evidence is present for solar cosmic-ray bombardment (i.e., ${ }^{26} \mathrm{Al} /{ }^{10} \mathrm{Be}$ greater than the ratio produced in meteorites by galactic cosmic-ray). Although some ${ }^{26} \mathrm{Al}$ might be produced by solar cosmic-rays at the ablation surface of meteorites, the distribution of ${ }^{10} \mathrm{Be}$ exposure ages in these particles is shifted toward shorter ages than those of ordinary chondrites.

An earlier paper (Nishiizumi et al., 1991) discussed two acceptable models ( $4 \pi$ and $2 \pi$ ) for the bombardment history of the particles bearing a clear solar cosmic-ray signature. In our view, the present data and other arguments favor the $4 \pi$ model, but these data are not yet conclusive (see below). Measurements of other nuclides, such as ${ }^{53} \mathrm{Mn}$ and ${ }^{59} \mathrm{Ni}$, can provide further useful discriminants.

Quartz-containing terrestrial pebbles were also collected from the same Lewis Cliff glacial moraine. The quartz separated from the pebbles contains in-situ produced ${ }^{10} \mathrm{Be},(2.74 \pm 0.09) \times 10^{6}$ atom $/ \mathrm{g}$, and ${ }^{26} \mathrm{AI},(11.8 \pm 1.1) \times 10^{6} \mathrm{atom} / \mathrm{g}$, respectively (Nishiizumi $e f$ al., 1992). The ${ }^{26} \mathrm{Al} /{ }^{10}$ Be ratio, $4.34 \pm 0.42$, is slightly lower than for a pure surface exposure and may correspond to a burial of the 
moraine beneath ice or soil for $\sim 0.5 \mathrm{Ma}$. If Lewis Cliff particles had similar terrestrial histories, ${ }^{26} \mathrm{Al}$ and ${ }^{10} \mathrm{Be}$ concentrations in these particles would be about $60 \%$ and $20-30 \%$ higher, respectively, when these particles fell to Earth than they are at present. However, there is insufficient basis now for meaningful corrections

\section{MODELS}

There are a number of qualitative arguments which favor bombardment of these objects mainly or entirely as small bodies (radius $<1 \mathrm{~cm}$ or even $<1 \mathrm{~mm}$; Raisbeck et al., 1985b). One is simply the relative number or mass flux of such bodies in interplanetary space, relative to that of meteoroids or larger bodies (Love and Brownlee, 1991; McDonnell, 1978). Another is the overwhelming predominance of particles showing high solar cosmic-ray production. Still, the two major model calculations of lifetime of small grains (Dohnanyi, 1978; Grun et al., 1985) so far made are in flat contradiction with our data since they suggest a mean lifetime of $2 \times 10^{4}$ years. A full exploration of the alternatives requires, in our view, a new model taking into account such constraints as the erosion rates of lunar rocks. However, this is beyond the scope of the present paper.

\section{CONCLUSIONS}

We confirm that nearly all spherules show unambiguous solar cosmic-ray effects. They have been bombarded in space for periods on order of $10^{5}-10^{7}$ years, at depths of gencrally $<1 \mathrm{~mm}$. The range of exposurc ages of particles is in good agreement with previous studies (Olinger et al., 1990; Raisbeck and Yiou, 1989). The concentrations of galactic cosmic-ray-produced nuclides in quartz pebbles from the same moraine suggests that the spherules too may have an appreciable terrestrial age.

We now see a few examples (6/42) consistent with bombardment only by galactic cosmic-rays, at greater depths, in meteoritesized bodies.

The solar cosmic-ray affected spherules can be divided further into three groups: (a) those bombarded in very small bodics comparable to their present size ( $4 \pi$ case); (b) those bombarded close to the surface of typical metcoroid-sized bodies $\left(4 \pi,{ }^{10} \mathrm{Be}=16-25\right.$ $\mathrm{dpm} / \mathrm{kg}$ ); and (c) those bombarded close to the surface of bodies of asteroid size $\left(2 \pi,{ }^{10} \mathrm{Be} \sim 10 \mathrm{dpm} / \mathrm{kg}\right)$. Using data for only two radionuclides alone, it is not possible to distinguish cases (a) and (c).

Dohnanyi (1978) and Grün et al. (1985) have calculated the survival times of micrometeoroids $(<1 \mathrm{~mm})$ in the inner Solar System to be $-2 \times 10^{4}$ ycars. Either these calculations or our understanding of the radionuclide data are in error. We suggest that the models for collisional destruction be reexamined.

Acknowledgments-We wish to thank R. C. Reedy and J. Masarik for Acknowledgmenis- We wis the solar cosmic-ray and galactic cosmic-ray variable discussion and for the solar cosmic-ray and galactic cosmic-ray calculations. Technical support Michel and M. Maurette for thoughtful measurements. We thank R. This work was supported by NASA grant NAG 9-33 and NAGW 3514 , by NSF grant OPP 9117558 (ANSMET) and under the auspices of the U.S. D.O.E. by LLNL under contract W-7405-Eng-48.

Editorial handling: L. Schultz

\section{REFERENCES}

Buindari N. Lal D. Rajan R, S., ARnold J. R., Marti K. and Moore C. B. (1980) Atmospheric ablation in meteorites: A study based on C. B. (1980) Als and neon isotopes. Nuclear Tracks 4, 213-262.

Cosmic ray D. PILACHOWSKI L. B. AND I HODGE P. W. (1979) Meteorite mining on the ocean floor (abstract). Lunar Planet. Sci. 10, 157-158.

BROWNE D DEACHAMP R. H. (1983) Meteor ablation spherules as chondrulc analogs. In Chondrules and their Origins (ed.
E. A. King), pp. 10-25. Lunar and Planetary Inst., Ilouston, Texas. DAVIS J. C., PROCTOR I. D., SOUTHON J. R, CAFFEE M. W., IEIKKINEN D. W., Roberts M. L., MOORE T. L., TURTfltaub K. W., NlLLSON D. E., LOYD D. H. AND VOGEL J. S. (1990) LLNL/UC AMS facility and research program. Nucl. Inst. Meth. B52, 269-272.

DohnanyI J. S. (1978) Particle dynamics. In Cosmic Dust (ed. J. A. M. McDonneli), pp. 527-605. John Wiley and Sons, New York.

GRUN E., ZOOK H. A., FECHTIG H. AND GIESE R. H. (1985) Collisional balance of the meteoritic complex. Icarus 62, 244-272.

HARVEY R. P. AND MAURETTE M. (1990) The best cosmic dust source in the world? The origin and significance of the Walcott Neve, Antarctica micro-meteorites (abstract). Lunar Planet. Sci. 21, 467-468.

KOFBERL C. AND HAGEN E. II. (1989) Extraterrestrial spherules in glacial sediment from the Transantarctic Mountains, Antarctica: Structure, mineralogy, and chemical composition. Geochim. Cosmochim. Acia 53, 937-944.

Love S. G. AND BrownleE D. E. (1991) Heating and thermal transformation of micrometeoroids entering the earth's atmosphere Icarus 89, 26-43

maurette M., Hammer C., Brownlee D. E., Reeit N. AND Thomsen H. II. (1986) Placers of cosmic dust in the blue ice lakes of Greenland. Science 233, 869-872.

MaUReTte M., JehanNo C., Robin E. and Hammer C. (1987) Characteristics and mass distribution of extraterrestrial dust from the Greenland ice cap. Nature 328, 699-702.

MCDONNELL J. A. M. (1978) Microparticle studies by space instrumentation. In Cosmic Dust (ed. J. A. M. McDonnell), pp. 337426. John Wiley and Sons, New York.

MillaRd H. T. AND FINKELMAN R. B. (1970) Chemical and mineralogical compositions of cosmic and terrestrial spherules from a marine sediment. J. Geophys. Res. 75, 2125-2134

MURRAY J. AND RENARD A. F. (1883) On the measurement characters of volcanic ashes and cosmic dust, and their origin in deep-sea sediment deposits. Proc. R. Soc. Edinburgh 12, 474-495.

MurRell M. T., DaVIS P. A. J., NishizUMI K. AND Mill. ard H. T. J (1980) Deep sea spherules from pacific clay: Mass distribution and influx rate. Geochim. Cosmochim Acta 44, 2067-2074.

NishiuzumI K. (1987) ${ }^{53} \mathrm{Mn}, 26 \mathrm{Al}, 10 \mathrm{Be}$, and $36 \mathrm{Cl}$ in meteorites: Data compilation. Nucl. Track Radiation Meas. 13, 209-273.

NishizUMI K., IMAMURA M., KOHL C. P., NAGAl H., KOBAYASII K., YOSHIDA K. YAMASIITA H., REEDY R. C., HONDA M. AND ARNOLD J. R. (1988) io Be profiles in lunar surface rock 68815 . Proc. Lunar Planet. Sci. Conf. 18th, 79-85.

NishizUMI K., ARNOLD J. R., FINK D., KLEIN J., MidDleton R., BROWNLEE D. E. AND MAURETTE M. (1991) Exposure history of individual cosmic particles. Earth Planet. Sci. Lett. 104, 315-324.

NISIIIZUMI K ARNOLD J R. KLEIN J., MIDDLETON R., BROWNLE. D. E., HAGFN E. H AND FAURE G. (1992) $10 \mathrm{Be}$ and $26 \mathrm{Al}$ in individual cosmic spherules from Antarctica (abstract). Lunar Planet. Sci. 23, 997-998.

OlNGer C. T. Maurette M., Walker R. M. AND Hohienberg C. M. (1990) Neon measurements of individual Greenland sediment particles: Proof of an extraterrestrial origin and comparison with EDX and Proof of an extres Earth Planet. Sci. Lett. 100, 77-93.

RAISBECK G. M. AND YIOU F. (1987) ${ }^{10} \mathrm{Be}$ and $26 \mathrm{Al}$ in micrometeorites from Greenland ice (abstract). Meteoritics 22, 485-486.

RAISBECK G. M. AND YIOU F. (1989) Cosmic ray exposure ages of cosmic spherules (abstract). Meteoritics 24, 318.

RAISBECK G. M., YIOU F. AND BROWNLEE D. (1985a) Unusually high concentration of ${ }^{10} \mathrm{Be}$ in a cosmic spherule: Possible evidence for irradiation outside the planetary solar system (abstract). Meteoritics 20, 734735 .

RaISBECK G. M., YIOU F., KLEIN J., MidDleton R. AND BROWNLEE D. (1985b) $26 \mathrm{Al} / 10 \mathrm{Be}$ in deep sea spherules as evidence of comctary origin. In Properties and Interactions of Interplanetary Dust (cds. R II. Giese and P. Lamy), pp. 169-174. D. Reidel, Dortrecht, The Netherlands.

REEDY R. C. (1987) Nuclide production by primary cosmic-ray protons Proc Lunar Planet. Sci. Conf. 17th, J. Geophys. Res. 92, E697-E702.

REEDY R. C. (1990) Cosmogenic-radionuclide production rates in minispherules (abstract). Lunar Planet. Sci. 21, 1001-1002

REEDY R C AND ARNOLD J. R. (1972) Interaction of solar and galactic cosmic-ray particles with the moon. $J$. Geophys. Res. 77, 537-555.

RFEDY R. C. AND MASARIK J. (1995) Production profiles of nuclides by galactic-cosmic-ray particles in small metcoroids (abstract). Workshop on Meteorites from Cold and Hot Deserts LPI-TR-95-01, (in press). 